\title{
Influence of particle size of nano zinc oxide on the controlled delivery of Amoxicillin
}

\author{
L. Palanikumar $\cdot$ S. Ramasamy $\cdot$ G. Hariharan • \\ C. Balachandran
}

Received: 10 May 2012/Accepted: 15 June 2012/Published online: 5 July 2012

(C) The Author(s) 2012. This article is published with open access at Springerlink.com

\begin{abstract}
A great effort has been exerted to develop drug carriers aiming at satisfying the requirements, such as safety, greater efficiency, predictable therapeutic response, and prolonged release period. The present study aims at developing the use of zinc oxide nanoparticles as a carrier as a function of particle size for amoxicillin drug delivery system. The amoxicillin-loaded zinc oxide nanoparticles have a good antibacterial activity against infectious Grampositive and Gram-negative bacteria. Zinc oxide nanoparticles have been prepared by wet chemical precipitation method varying the $\mathrm{pH}$ values. Particle size and morphology of the as-prepared $\mathrm{ZnO}$ powders are characterized by X-ray diffraction, Fourier transform infrared spectroscopy and transmission electron microscope. Drug loading, in vitro drug release and antibacterial activity have been analyzed. Maximum zone of inhibition is observed for Staphylococcus epidermis. The results show that inhibitory efficacy of drug-loaded $\mathrm{ZnO}$ nanoparticles is very much dependent on its chosen concentration, drug loading, and size.
\end{abstract}

Keywords Amoxicillin $\cdot \mathrm{ZnO}$ nanoparticles · Controlled release $\cdot$ Antibacterial activity

L. Palanikumar $\cdot$ S. Ramasamy $(\bowtie)$

Crystal Growth Centre, Anna University,

Chennai 600025, India

e-mail: sinna_ramasamy@yahoo.com

G. Hariharan

Institute for Ocean Management, Anna University,

Chennai 600025, India

C. Balachandran

Division of Microbiology, Entomology Research Institute,

Loyola College, Chennai 600034, India

\section{Introduction}

Over the past few years, local delivery systems have attracted much attention due to their efficacy to improve the ingrowth and regeneration of bones and teeth (Kim et al. 2004). Drugs, such as antibiotics, anti-tumors, and growth factors, have been administered to the defect regions to induce therapeutic effects (Di Silvio and Bonfield 1999). A great deal of effort has been exerted to develop drug carriers, in the form of foams, films, and microspheres, aiming at satisfying the requirements, such as safety, greater efficiency, predictable therapeutic response and prolonged release period (Gautier et al. 2001). Due to the large surface-to-volume ratio the nanoparticles are very useful for attaching drug molecules and other compounds (De Jong and Borm 2008). Nanoscale devices, smaller than $50 \mathrm{~nm}$, can easily enter most cells and circulate through the body through blood vessels (Courrier et al. 2002). The advances in micro and nanofabrication technology have enhanced the tools available to create clinically important therapeutic applications ( $\mathrm{Lu}$ and Chen 2004).

Controlled drug delivery is the technology by which the drugs can be released at a predetermined rate for a long period of time in the blood stream or delivered at the target site (Kamaly et al. 2012). Unlike the traditional oral, intravenous drug delivery methods whereby the drug is distributed to both healthy and diseased tissue, in controlled local drug delivery high concentration of drug is achieved at the infected site. This leads to increase in therapeutic index and therapeutic efficacy and abridged side effects to other organs (Melville et al. 2008; Noel et al. 2008). Drug stability, optimized drug absorption, treatment continuation in natural phase improvement in pharmacokinetic characteristics of drug can be achieved by localized 
drug delivery (Smola et al. 2008). In controlled drug delivery system, the carrier plays a vital role since they incorporate the drug, retain it, and release it progressively with time. So, properties such as (1) drug incorporation and release, (2) formulation stability and shelf life, (3) biocompatibility, (4) bio-distribution, and (5) functionality must be analyzed thoroughly when choosing a carrier for delivery of drugs. The drug release from any carrier depends upon solubility of drugs, microstructure of carrier, degradation of carrier, and the bond between the drug and carrier (De Jong and Borm 2008). The application of nanotechnology to medical applications, commonly referred to as "nanomedicine", seeks to deliver a new set of tools, devices and therapies for treatment of human disease (Rasmussen et al. 2010). The potential use of zinc oxide $(\mathrm{ZnO})$ and other metal oxide nanoparticles in biomedical and cancer applications is gaining attention in the scientific and medical communities, largely due to the physical and chemical properties of these nanomaterials (Rasmussen et al. 2010). $\mathrm{ZnO}$ is one of the five zinc compounds which are currently recognized as safe for nutrients by the US Food and Drug Administration (21CFR182.8991). ZnO nanoparticles (NPs) are widely used in many consumer products like cosmetics, toothpaste, textiles, and skin lotions (Ng et al. 2010).

Amoxicillin trihydrate is a semi synthetic antibiotic with a broad spectrum of bactericidal activity against many Gram-positive and Gram-negative, aerobic and anaerobic microorganisms. It does not resist destruction by $\beta$-lactamases; therefore, it is not effective against $\beta$-lactamaseproducing bacteria. Chemically, it is $\mathrm{d}(-)$-a-amino- $p-/ /$ hydroxybenzyl penicillin trihydrate. Amoxicillin is an excellent agent to treat otitis media, bacterial sinusitis, and bacterial exacerbations of bronchitis, acute lower-urinarytract infections, gonorrhea, and typhoid (Khuroo et al. 2008). Staphylococcus aureus and Staphylococcus epidermidis are natural inhabitants of human and animal skin, but it can sometimes cause infections that affect many organs (Bhunia 2008). S. aureus is one among the most important pathogens that cause bone and joint infections, soft tissue and overwhelming sepsis and express many surface adhesions that promote attachment to plasma and extra cellular matrix (ECM) proteins of the host cell (Venkatasubbu et al. 2011). The pathogenic bacteria Klebsiella pneumonia and Enterobacter aerogenes are the major causative agents of noso-comial infections (Saonuam et al. 2008). Serotype paratyphi B var. L (+) tartrate $(+)$ causes a typical Salmonella gastroenteritis instead of enteric fever (Prager et al. 2003).

In the present work different sizes of zinc oxide were synthesized in nano form and characterized. Amoxicillin was loaded to these $\mathrm{ZnO}$ nanoparticles. The various parameters for drug loading were optimized. The drug loading percentage, stirring time and the influence of drug release profile on these parameters were analyzed. The interaction between nanoparticles and drug was analyzed. Antibacterial response of drug-loaded nanoparticles against infectious Gram-positive and Gram-negative microbes was investigated.

\section{Materials and methods}

Synthesis and characterization of $\mathrm{ZnO}$ nanoparticles

Zinc oxide nanoparticles were synthesized with a slight modification suggested by $\mathrm{Wu}$ et al. (2006) from aqueous solutions of zinc nitrate $\left(\mathrm{Zn}\left(\mathrm{NO}_{3}\right)_{2} \cdot 6 \mathrm{H}_{2} \mathrm{O}\right)$ (purchased from Fischer Chemicals, Mumbai, India; Purity $96 \%$ ) and hexamethyltetramine (HMT) $\left(\mathrm{C}_{6} \mathrm{H}_{12} \mathrm{~N}_{4}\right)$ (purchased from Qualigens Chemicals, Mumbai, India; Purity $99 \%$ ). The two chemicals were mixed separately with milli-Q water to a concentration of $0.05 \mathrm{M}$ for the $\left(\mathrm{Zn}\left(\mathrm{NO}_{3}\right)_{2}\right)$ solution and 1.5 $\mathrm{M}$ for the HMT solution. The separate solutions were stirred for $30 \mathrm{~min}$ each and then mixed with $130 \mathrm{rpm}$ stirring. The solutions were adjusted to the desired $\mathrm{pH}$ (5.0, 6.0 and 7.2) and heated to $80{ }^{\circ} \mathrm{C}$ for $45 \mathrm{~min}$. The product was collected by centrifugation (Compufuge, Model CPR 32, Remi Electrotechnik Limited, Thane, India). The ammonium hydroxide solution (one normality solution) was added to $\mathrm{pH} 5.0$ synthesized solutions to enhance the formation of $\mathrm{ZnO}$ at $80^{\circ} \mathrm{C}$ (Wu et al. 2006).

\section{Particle characterization}

Powder X-ray Diffraction (XRD, Seifert, JSO-DE BYEFLEX 2002, Germany) was used to identify the crystalline phase composition and purity. The phase was found to be hexagonal and no impurity peaks were found. The morphology and grain size of the $\mathrm{ZnO}$ were observed by TECNAI G ${ }^{2}$ Model T-30 S-twin high-resolution transmission electron microscopy (HRTEM). The quality of the ZnO NPs was analyzed by FTIR (FTIR, Perkin Elmer Spectrum One). The size distributions were performed in a dilute aqueous nanoparticle suspension at $\mathrm{pH} 7.0$ with particle size analyzer (Malvern S particle size analyzer).

\section{Drug loading}

In order to load the drug into $\mathrm{ZnO}$ nanoparticles, amoxicillin trihydrate was dissolved in $100 \mathrm{ml}$ of distilled water at different concentrations $(1,3,5$ and $10 \%) .1 \mathrm{~g}$ of different sizes of $\mathrm{ZnO}$ nanoparticles was added to all the three drug solutions and stirred using magnetic stirrer at $600 \mathrm{rpm}$ for various time periods $(30,60$ and $120 \mathrm{~min}$ ) at room temperature. Then the solution was left undisturbed 
overnight. The suspension was then centrifuged at $5,000 \mathrm{rpm}$ for $5 \mathrm{~min}$ and the supernatant and precipitate were separated. The amount of loaded drug was determined by finding the difference in amoxicillin concentration in the aqueous solution before and after drug loading. Percentage of drug loading was calculated using the following equation:

Percentage of drug loading $=[(A-B) / A] \times 100$

where $A$ and $B$ represent the initial and final drug concentration of the aqueous drug solution (Hamblett et al. 2004; Venkatasubbu et al. 2011). The attachment of amoxicillin with $\mathrm{ZnO}$ nanoparticles was analyzed by FTIR (FTIR, Perkin Elmer Spectrum One).

In vitro drug release studies

In order to determine the drug release profile, $100 \mathrm{mg}$ of the drug loaded $\mathrm{ZnO}$ nanoparticles was introduced into a screw-capped $(100 \mathrm{ml})$ glass bottle containing $50 \mathrm{ml}$ of phosphate-buffered saline (PBS) medium at $37{ }^{\circ} \mathrm{C}$ and $\mathrm{pH}$ 7.4 under sterile condition. In vitro drug release study was done for a period of $650 \mathrm{~h} .5 \mathrm{ml}$ samples were withdrawn by a pipette and centrifuged at 5,000 rpm and replaced immediately with $5 \mathrm{ml}$ of fresh PBS medium, which was accounted for when calculating the amount released. Amoxicillin concentration in the supernatant was measured spectrophotometrically at a wavelength of $230 \mathrm{~nm}$. The $\mathrm{pH}$ in the media at different intervals was estimated. The experiments were repeated thrice.

\section{Antimicrobial assay}

The antibacterial assay of drug-loaded $\mathrm{ZnO}$ nanoparticles with different sizes was tested by disc-diffusion method (Jayaseelan et al. 2012). The following bacteria were used for the experiments: Salmonella paratyphi-B, Klebsiella pneumoniae MTCC 109, Bacillus subtilis MTCC 441, Enterobacter aerogenes MTCC 111 and Staphylococcus epidermidis MTCC 3615. The reference cultures were obtained from Institute of Microbial Technology (IMTECH), Chandigarh, India-160 036. Petri plates were prepared with $20 \mathrm{ml}$ of sterile Mueller-Hinton agar (MHA) (Himedia, Mumbai). The test cultures were swabbed on the top of the solidified media and allowed to dry at room temperature for $10 \mathrm{~min}$. The suspension of drug loaded nanoparticles (in milli-Q water) was used to prepare 50, 100 and $200 \mu \mathrm{g} \mathrm{ml}^{-1}$ added to each well separately $(8 \mathrm{~mm}$ diameter). Amoxicillin trihydrate $(25 \mu \mathrm{g} / \mathrm{disc}$; purchased from Himedia Chemicals Ltd., Mumbai, India) was used as positive control. The plates were incubated for $24 \mathrm{~h}$ at $37^{\circ} \mathrm{C}$. Zones of inhibition were recorded in millimeters by repeating the experiment thrice for each concentration.
Statistical analysis

Experiments were repeated thrice and results were presented as means and standard deviations from the three replicates. Drug release, $\mathrm{pH}$ buffer data, and antimicrobial assay were evaluated by one-way analysis of variance (ANOVA) in combination with Tukey's multiple comparison tests. A significance level of $P<0.05$ was considered statistically significant.

\section{Results and discussion}

The present study employed a low-temperature synthesis method to prepare ZnO NPs. Zinc nitrate and HMT solutions were mixed at $80{ }^{\circ} \mathrm{C}$ for $45 \mathrm{~min}$ at different $\mathrm{pH}$. After precipitation of $\mathrm{ZnO}$, the $\mathrm{pH}$ value was found to be 8.2. The XRD pattern of synthesized $\mathrm{ZnO}$ nanoparticles demonstrated that the nano $\mathrm{ZnO}$ to be crystalline in nature, and the diffraction peaks matched very well with hexagonal zincite phase of $\mathrm{ZnO}$ (Fig. 1). The diffraction pattern and inter-planar spacing closely matched those in the standard diffraction pattern of $\mathrm{ZnO}$ (powder diffraction file ICDD 36-1451: $a=3.249 \AA$ and $c=5.206 \AA$ ). The XRD peaks show (100), (002), (101), (102), (110), (103), (200), and (201) reflection lines of hexagonal zincite phase of $\mathrm{ZnO}$ particles. No characteristic peaks of any impurities were found suggesting good-quality $\mathrm{ZnO}$ nano powders. The particle size based on broadening has been analyzed by Scherrer formula, modified forms of Williamson-Hall analysis, and size-strain plot method. The crystalline size can be calculated using the following equation:

$\left(d_{h k l} \beta_{h k l} \cos \theta\right)^{2}=K / D\left(d_{h k l}^{2} \beta_{h k l} \cos \theta\right)+(\varepsilon / 2)^{2}$

where $K$ is the constant that depends on the shape of the particles. The particle size has been determined from the slope of linearly fitted data. The root of the $y$ intercept gives the strain (Zak et al. 2011).

The functional or composition quality of the synthesized product has been analyzed by the FTIR spectroscopy. Figure 2 shows the FTIR spectrum acquired in the range of $400-4,000 \mathrm{~cm}^{-1}$. The band at $535 \mathrm{~cm}^{-1}$ corresponds to the stretching vibration of $\mathrm{Zn}-\mathrm{O}$ bond. The broad absorption bands in the range $3,900-2,350 \mathrm{~cm}^{-1}$ and $1,637 \mathrm{~cm}^{-1}$ correspond to the presence of the surface hydroxyl groups (Sharma et al. 2009). C-OH stretching $\left(1,387 \mathrm{~cm}^{-1}\right.$ ) is detected from the FT-IR spectrum (Song et al. 2008). The band at $1,387 \mathrm{~cm}^{-1}$ corresponds to the $\mathrm{CH}_{2}$ deformation, and absorption bands at $1,235-1,125 \mathrm{~cm}^{-1}$ are responsible for CN stretch. $998 \mathrm{~cm}^{-1}$ and $897 \mathrm{~cm}^{-1}$ correspond to $\mathrm{CH}_{2}$ rock (Bernstein et al. 1994). The TEM image of pure $\mathrm{ZnO}$ nanoparticles is presented in Fig. 3. The insert Fig. 3 is particle size distribution as measured by dynamic light 
Fig. 1 XRD Pattern of $\mathrm{ZnO}$ prepared at different $\mathrm{pH}$. a Asprepared, b $\mathrm{pH} 6.0$, c $\mathrm{pH} 5.0$

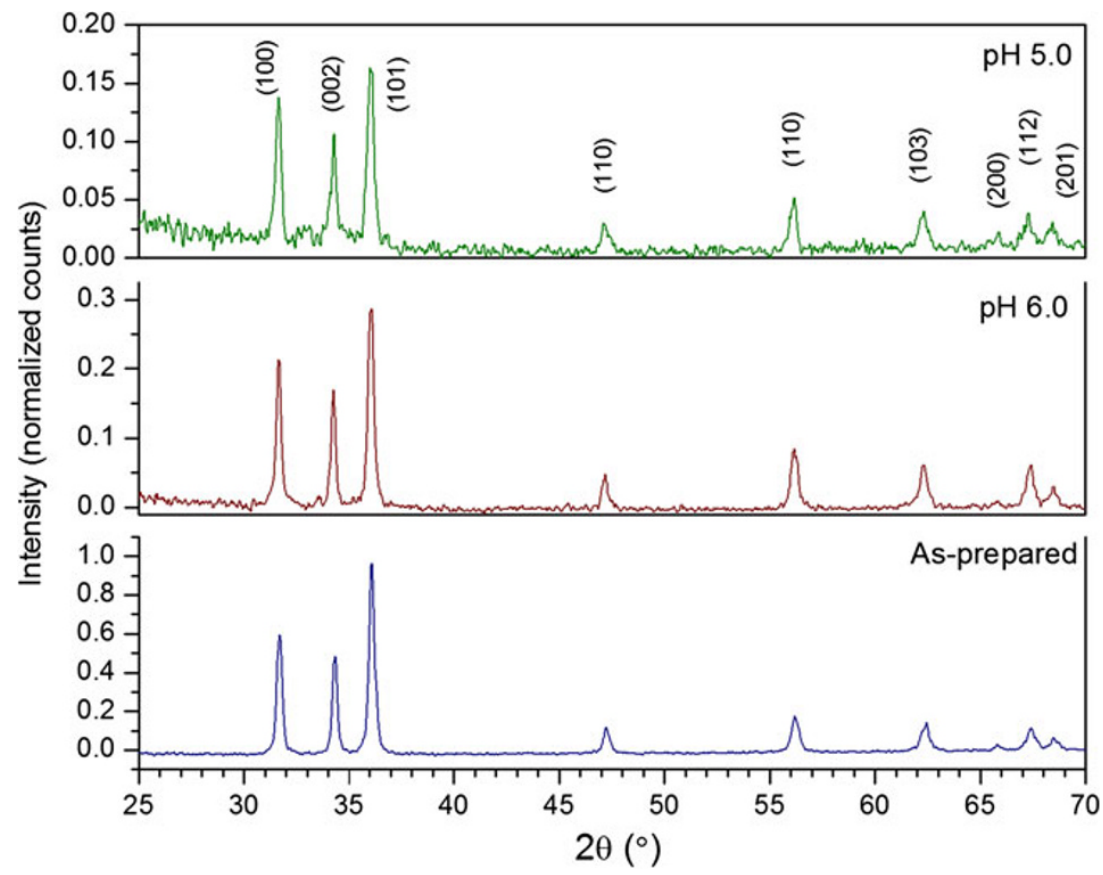

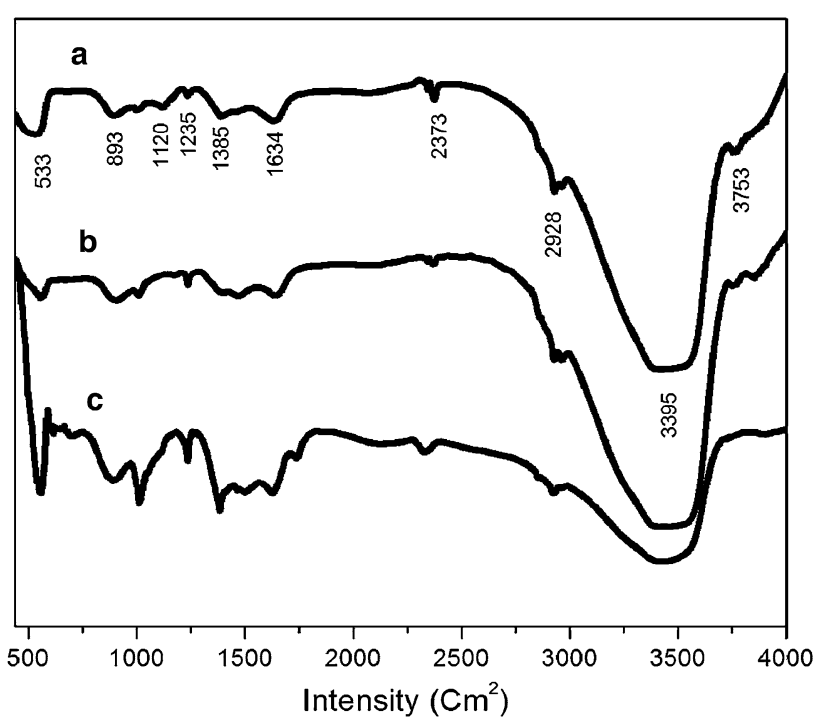

Fig. 2 FTIR spectrum of as-prepared $\mathrm{ZnO}$ nanoparticles. a Asprepared, b $\mathrm{pH} 6.0, \mathbf{c} \mathrm{pH} 5.0$

scattering (DLS). The TEM images confirm the formation of hexagonal structure of $\mathrm{ZnO}$ and are in agreement with the XRD results. The particle size of the $\mathrm{ZnO}$ prepared at different $\mathrm{pH}$ are $38 \pm 2,25 \pm 4$ and $15 \pm 4 \mathrm{~nm}$ in as-prepared, $\mathrm{pH} 6.0$ and 5.0 respectively.

The structure of the amoxicillin-loaded $\mathrm{ZnO}$ nanoparticles analyzed using FTIR spectroscopy is shown in Fig. 4. Characteristics bands of both $\mathrm{ZnO}$ and amoxicillin are observed for all $\mathrm{ZnO} /$ drug samples. The $\mathrm{ZnO}$ nanoparticles loaded with drug represent mixed bands typical of $\mathrm{ZnO}$ nanoparticles, where $3,900-2,375 \mathrm{~cm}^{-1}$ corresponds to the presence of the surface hydroxyl groups and amoxicillin major peaks observed at $3,359 \mathrm{~cm}^{-1}$ (amide $\mathrm{NH}$ and phenol $\mathrm{OH}$ stretch), 2,971 and $2,375 \mathrm{~cm}^{-1}$ benzene ring $\mathrm{CH}$ stretch, $1,583 \mathrm{~cm}^{-1}$ benzene ring $\mathrm{C}=\mathrm{C}$ stretch, $1,398 \mathrm{~cm}^{-1}$ (NH bend $\mathrm{CB}$ stretch combination band and $\mathrm{NH}^{3+}$ symmetric deformation (Kumar et al. 2011). The peaks observed between 1,573 and $739 \mathrm{~cm}^{-1}$ in amoxicillin-loaded $\mathrm{ZnO}$ nanoparticles comply with peak of $\mathrm{ZnO}$ and amoxicillin trihydrate and indicate that the amoxicillin is compatible with $\mathrm{ZnO}$.

\section{Drug loading}

The drug loading efficiency of $\mathrm{ZnO}$ nanoparticles has been examined as described previously. It is dependent on the concentration of drug, size of nanoparticles and the ratio of drug and ZnO NPs. The drug loading percentage increases with increase in these parameters. It increases and becomes constant at a particular level. The variation in drug loading with change in drug concentration is shown in Table 1. For 1 and $3 \%$ drug concentration, the drug loading is 60 and $80 \%$ and it increases to $90 \%$ at 5 and $10 \%$ drug concentration and remains to be $90 \%$ for both these concentrations for $15 \mathrm{~nm}$ size $\mathrm{ZnO}$. The drug loading is $87 \%$ for 5 and $10 \%$ drug concentration in 25 and $38 \mathrm{~nm} \mathrm{ZnO} \mathrm{NPs.}$ The variation in drug loading with change in stirring time is given in Table 2. With 1 and $3 \%$ drug concentration and stirring at $30 \mathrm{~min}$, the drug loading is found to be 37 and $49 \%$ and it increases to 62 and $79 \%$ at $5 \%$ and $10 \%$ drug concentration for $15 \mathrm{~nm}$ ZnO NPs. Maximum drug 

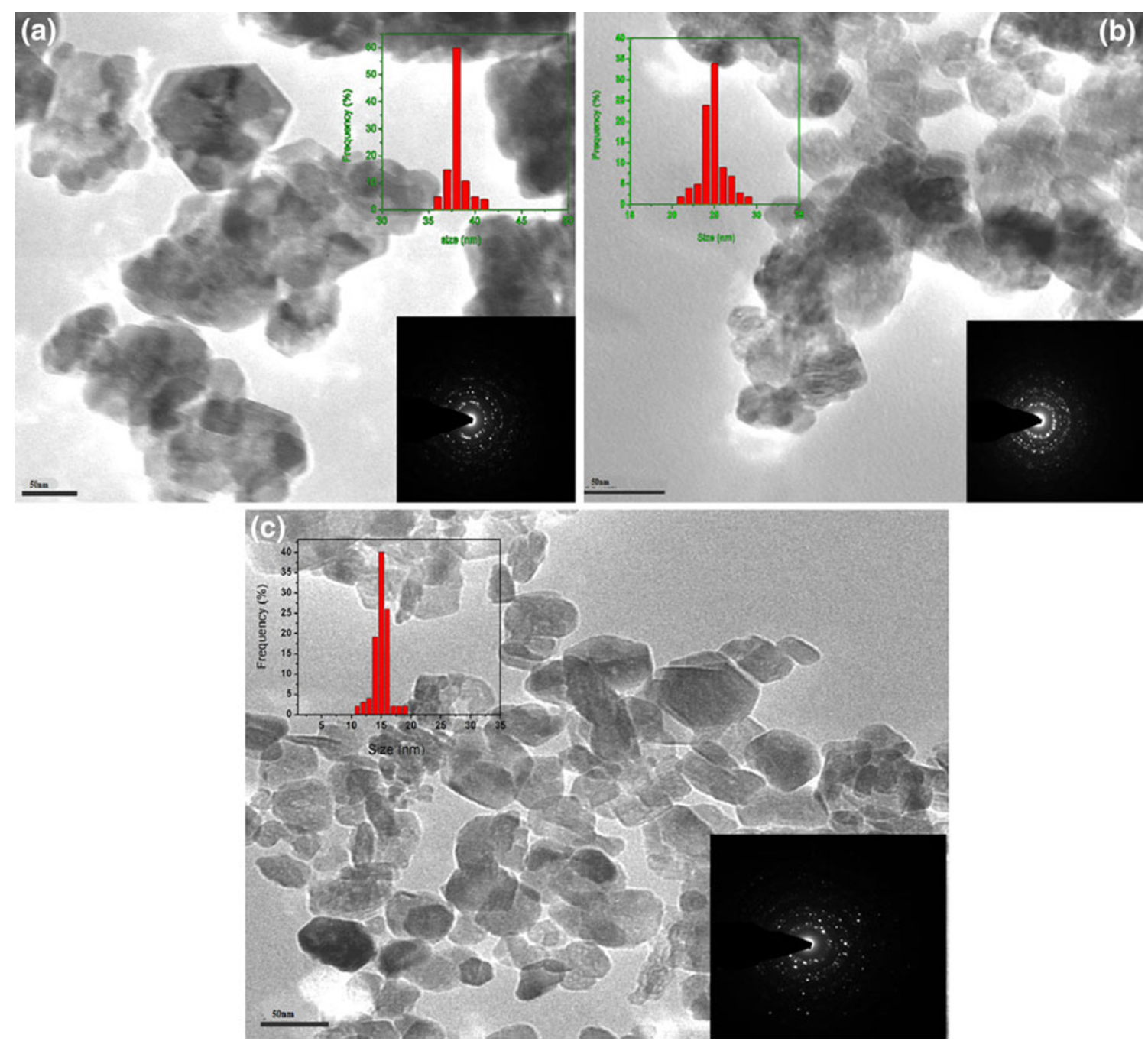

Fig. 3 TEM images of $\mathrm{ZnO}$ nanoparticles prepared at different $\mathrm{pH}$ (inset picture describes particle distribution and size in aqueous suspension). a As prepared, b $\mathrm{pH}$ 6.0, c $\mathrm{pH} 5.0$

loading is obtained at 60 and $120 \mathrm{~min}$ and then it becomes constant for all the three different sizes of nanoparticles.

In vitro drug release

Many carrier systems are used for the controlled delivery of amoxicillin. Polyethyleneglycol-coated polycyanoacrylate nanoparticles loaded with amoxicillin have been used for phagocytic uptake (Fontana et al. 2001). The study reports the release profile of amoxicillin at different $\mathrm{pH} 7.4$, 4.0 and 1.1 in comparison with urease. This work reports the release studies at $\mathrm{pH} 7.4$ and in human plasma evidences that the amoxicillin release occurs with a biphasic profile with an initially rapid followed by zero-order kinetics. Nanoparticles incorporated in pH-sensitive hydrogels as amoxicillin delivery for eradication of Helicobacter pyroli (Chang et al. 2010). The results of drug releasing in vitro study clearly indicate that the amount of amoxicillin released from nanoparticles incorporated in hydrogels in $\mathrm{pH} 1.2$ is relatively low (14\%), compared with that from only nanoparticles $(50 \%)$. The sustained release of amoxicillin from chitosan tablets was investigated by Sahasathian et al. (2007). These authors have shown that chitosan with the particle size less than $75 \mu \mathrm{m}$ is able to provide a significantly improved sustained release profile of amoxicillin compared with release profile of a commercial capsule. Amoxicillin release kinetics of gamma-irradiated chitosan/pHEMA membranes have shown that the amount of drug release is dependent on membrane network crosslinking due composition, radiation and membrane thickness (Casimiro et al. 2007).

In this work, amoxicillin has been loaded on $\mathrm{ZnO}$ to investigate the efficacy of the drug delivery system. The different drug release profiles are illustrated in Fig. 5. The estimated percentages of drug released in $648 \mathrm{~h}$ are found to be 60,80 , and $90 \%$ from $1,3,5$, and $10 \%$ drug-loaded 


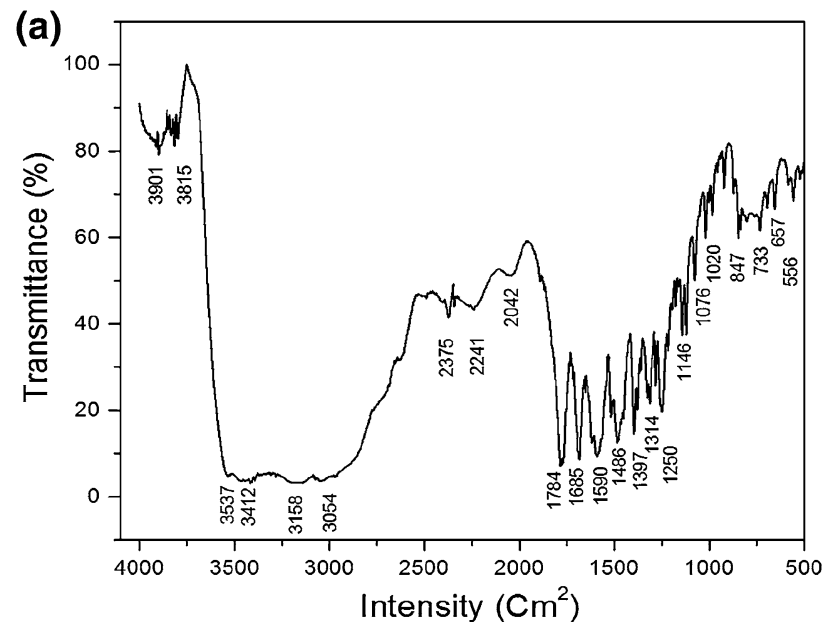

(b)

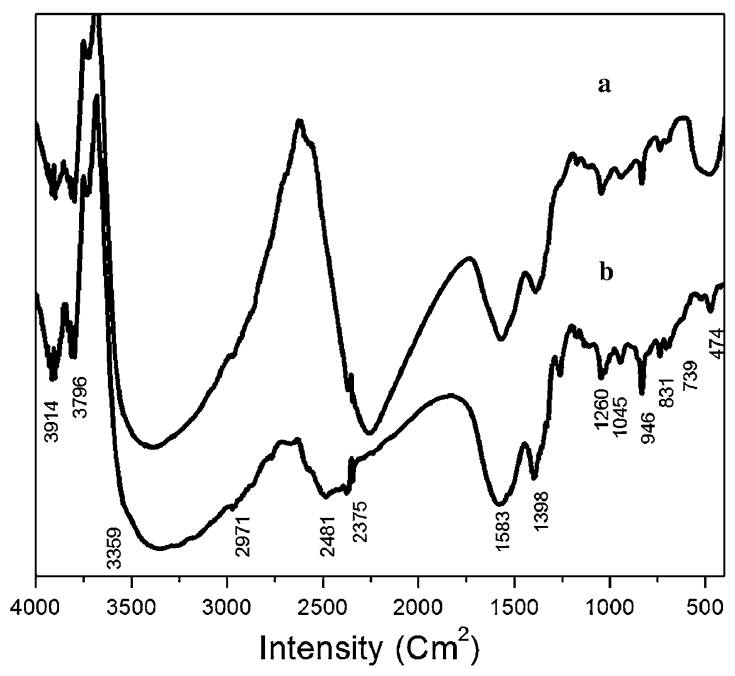

Fig. 4 FTIR Spectrum of drug loaded nanoparticles. a FTIR spectrum of amoxicillin, b FTIR spectrum of drug loaded $15 \mathrm{~nm}$ $\mathrm{ZnO}$ NPs at $a 1: 3$ ratio and $b 1: 5$ ratio

Table 1 Drug loading percentage with various concentrations
Table 2 Drug loading percentage with different stirring time

\begin{tabular}{lcl}
\hline Drug concentration $(\%)$ & Stirring time $(\mathrm{min})$ & Drug loading \\
\hline $15 \mathrm{~nm}$ ZnO NPs & 30 & \\
1 & 60 & 37 \\
& 120 & 60 \\
& 30 & 60 \\
3 & 60 & 49 \\
& 120 & 80 \\
& 30 & 80 \\
5 & 60 & 62 \\
& 120 & 90 \\
& 30 & 90 \\
10 & 60 & 79 \\
& 120 & 90
\end{tabular}

$25 \mathrm{~nm} \mathrm{ZnO} \mathrm{NPs}$

$60 \quad 87$

$25 \mathrm{~nm} \mathrm{ZnO} \mathrm{NPs}$

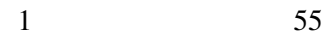

$3-75$

$5 \quad 87$

$10-87$

$38 \mathrm{~nm} \mathrm{ZnO}$ NPs

\begin{tabular}{ll}
1 & 55 \\
3 & 75 \\
5 & 87 \\
10 & 87 \\
\hline
\end{tabular}

1

31

$\begin{array}{ll}30 & 31 \\ 60 & 55\end{array}$

$120 \quad 55$

3

34

$\begin{array}{lll}60 & 75\end{array}$

$5 \quad 30 \quad 45$

$\begin{array}{lll}60 & 87\end{array}$

$10-30 \quad 54$

$60 \quad 87$

$120 \quad 87$

$38 \mathrm{~nm} \mathrm{ZnO} \mathrm{NPs}$

1

$30-27$

$60-55$

$120 \quad 55$

330

$60 \quad 75$

$120 \quad 75$

$30 \quad 36$

$120 \quad 87$

$\begin{array}{rr}30 & 46 \\ 10 & 60\end{array}$

$120 \quad 87$

31
5
5
5
5
5
87
87
87
87
27
55
57
87
75
75
36

samples, respectively. The drug release increases gradually over a period of time. This shows that the drug is released in a controlled manner. The amount of drug released in $24 \mathrm{~h}$ of time is well above the minimum inhibition concentration of amoxicillin which is up to $25 \mu \mathrm{g} \mathrm{ml}^{-1}$ for infectious pathogens. Such an observed release profile will provide a rapid delivery of drug to give antibacterial effects at the infected site and a sustained release to aid long-term 
Fig. 5 Drug release profile in a Amoxicillin loaded on $15 \mathrm{~nm} \mathrm{ZnO}$ nanoparticles, b Amoxicillin loaded on $25 \mathrm{~nm} \mathrm{ZnO}$ nanoparticles, c Amoxicillin loaded on $38 \mathrm{~nm}$ $\mathrm{ZnO}$ nanoparticles
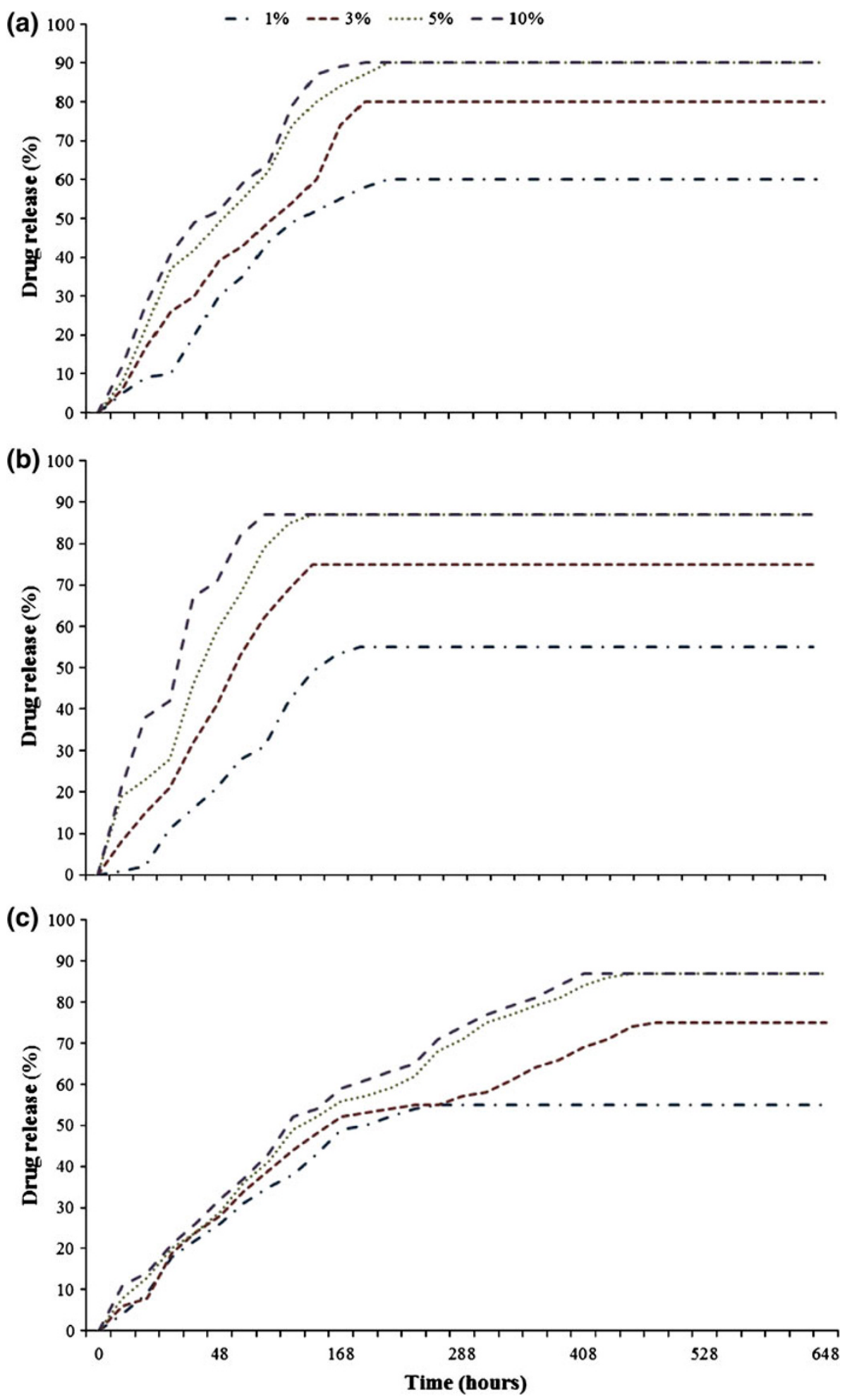

healing and avoid the toxic and adverse systemic effects caused by high concentration of antibiotics. The release of drug from $\mathrm{ZnO}$ NPs exhibits a two stage release mechanisms. The drug release is high during the initial time and then it reduces and becomes stable. Amoxicillin release during the initial burst stage is due to adsorption of drug molecules that are located on the surface of the particles (Fontana et al. 2001). These particles do not strongly interact with the $\mathrm{ZnO}$ NPs. During the in vitro drug release analysis, the $\mathrm{ZnO}$ absorbs the surrounding fluids into the nanoparticles. This leads to the dissolution and exclusion of the loaded amoxicillin. The smaller the particles, the more 
Fig. 6 Antimicrobial activity of amoxicillin-loaded $\mathrm{ZnO}$ nanoparticles in a gram-positive bacteria, b Gram-negative

bacteria. $* P<0.05$ statistically significant when compared with control
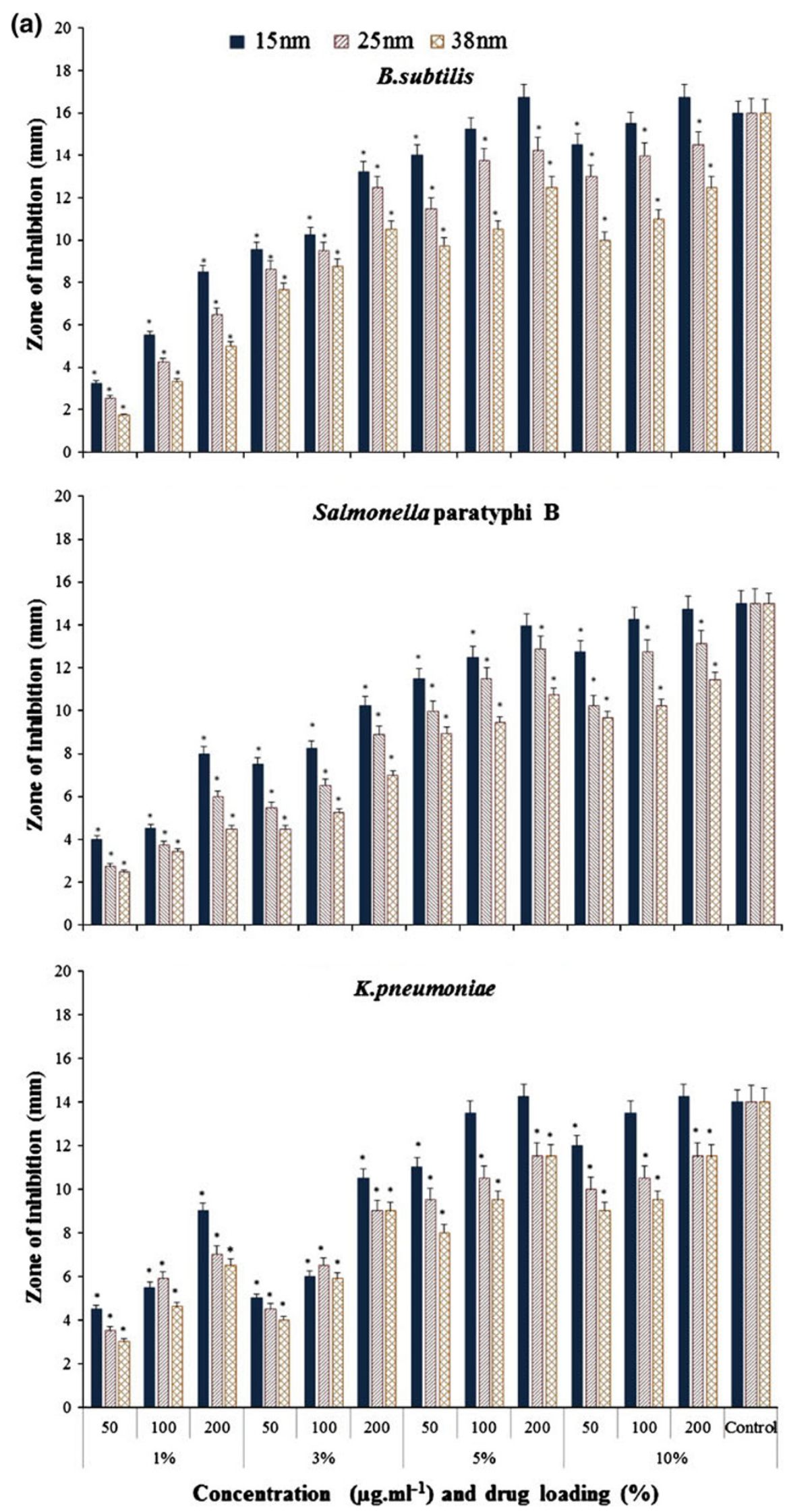
Fig. 6 continued
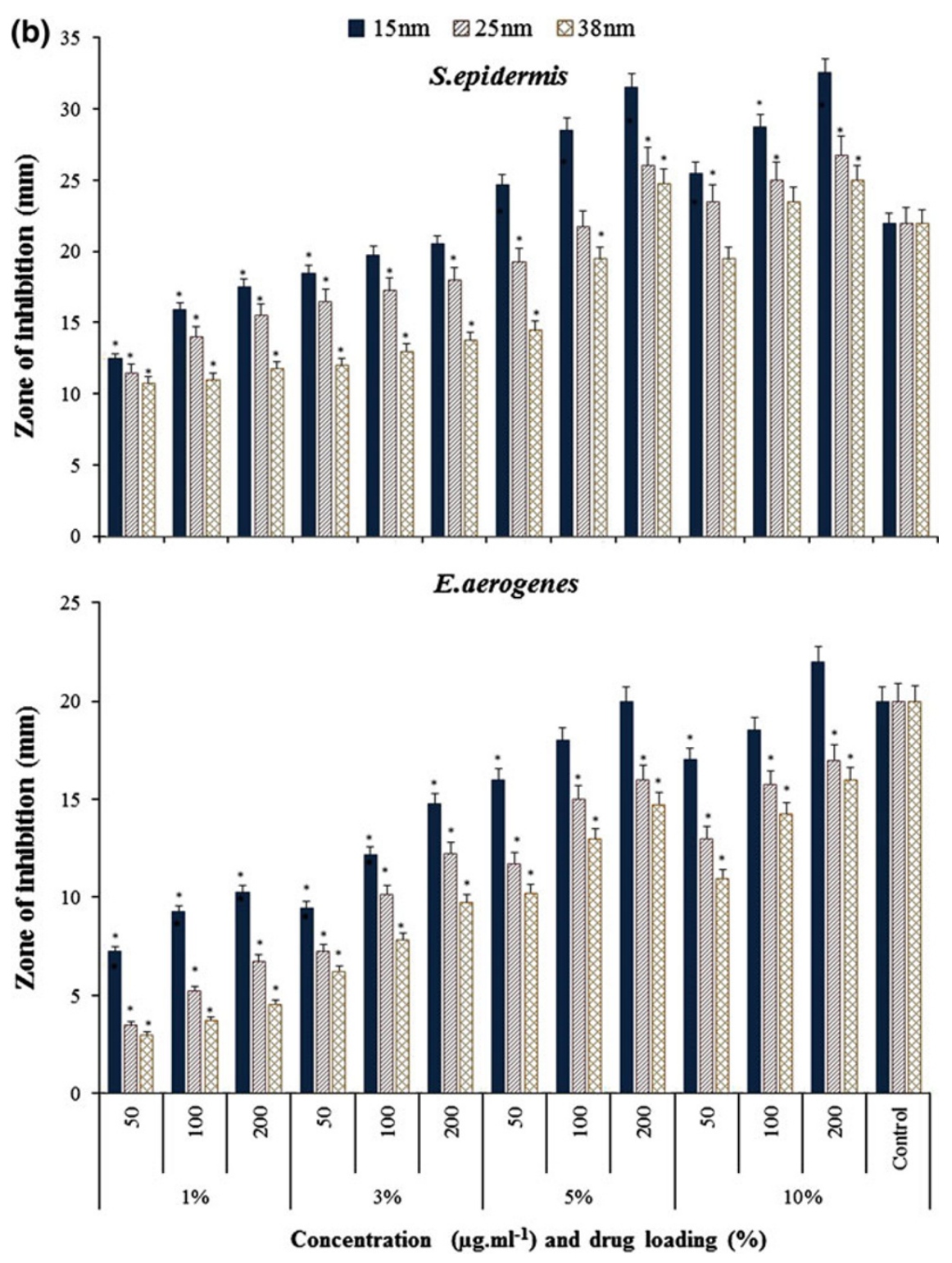

the exposure of amoxicillin to the fluid. When the loosely adsorbed drug has almost completely desorbed, the drug release becomes slow. The slow release of amoxicillin is due to the incorporation of the drug $\mathrm{ZnO}$ NPs.

\section{Antibacterial activity}

The re-emergence of infectious diseases poses a serious threat to public health. The increasing rate of the appearance of antibiotic-resistant strains in a short period of time within both Gram-positive and Gram-negative microorganisms is a major public health concern (Jones et al. 2008). Alternative therapeutics to control and prevent the spread of infections in both community and hospital environments are required (Sharma et al. 2009). The results of antibacterial activity of different sizes of drug-loaded $\mathrm{ZnO}$ NPs are shown in Fig. 6a and b. The zone of inhibition (in $\mathrm{mm}$ ) reflects magnitude of susceptibility of the microorganism. The strains susceptible to nanoparticles exhibit larger zone of inhibition, whereas resistant strains exhibit smaller one. Significant difference between each concentration has been compared. Maximum zone of inhibition has been observed for S. epidermis. Increase in drug loading concentration significantly $(P<0.05)$ increases the zone of inhibition from 1 to $3 \%$ drug concentration. Insignificant differences between zones of inhibition are observed for 5 and $10 \%$ drug concentration. Highest zones of inhibition are observed for drug-loaded $15 \mathrm{~nm} \mathrm{ZnO}$ NPs.

The antibacterial activity of ZnO NPs from the present results suggests that $\mathrm{ZnO}$ nanoparticles may play differential response to various tested microorganisms. This may be consistent with the prediction that $S$. epidermis can 
metabolize $\mathrm{Zn}^{2+}$ as an oligo element (Roselli et al. 2003). Similarly, metal-ion homeostasis is important for bacterial life because of their involvement in the regulation of a wide array of metabolic functions asco-enzymes, cofactors, and catalysts, and as structural stabilizers of enzymes and DNA-binding proteins (Padmavathy and Vijayaraghavan 2003). However, excess metal or metal ions are toxic for bacterial cells. Therefore, certain bacteria have developed mechanisms to regulate the influx and efflux processes to maintain the steady intracellular concentration of metal ions, including the $\mathrm{Zn}^{2+}$ ion (Gaballa et al. 2002). The higher antibacterial activity of drug loaded $\mathrm{ZnO}$ nanoparticles in S. epidermis may involve the production of reactive oxygen species (ROS) and the deposition on the surface or accumulation in the cytoplasm of the cells as observed in earlier studies for S. aureus (Raghupathi et al. 2011). The results obtained in our study indicate that the inhibitory efficacy of drug-loaded $\mathrm{ZnO}$ nanoparticles is very much dependent on its chosen concentration, drug loading, and size which are similar to other related findings (Yin et al. 2010; Wahab et al. 2010).

Amoxicillin trihydrate is currently marketed as tablets (floating tablets) of 250 and $500 \mathrm{mg}$. The long-term administration of amoxicillin trihydrate is required against Streptococcal pharyngitis (http://www.healthystock.net/drugs/ amoxicillin.shtml).

The presently available conventional therapy is associated with a number of drawbacks such as highly variable absorption and low bioavailability after oral administration (Bhosale et al. 2011). Furthermore, with increase in dose, there is decrease in bioavailability. Maximal therapeutic efficacy needs to be coupled with minimal toxicity, a goal which can be achieved by formulating drugs with nanoparticles (Horwitz et al. 2010).

\section{Conclusion}

A drug delivery system with different sizes of $\mathrm{ZnO}$ NPs has been developed to treat against infectious bacteria. $\mathrm{ZnO}$ NPs can be used as drug delivery system for the controlled delivery of amoxicillin. The antimicrobial property increases with increase in the drug loading and becomes stable at 5 and $10 \%$ drug loading. The drug loading depends on the size of nanoparticles, concentrations of drug, and stirring time. The drug loading increases with increase in stirring time and drug concentration. The drug release profile from all three sizes of $\mathrm{ZnO}$ NPs shows a controlled release. The antibacterial investigations of amoxicillin loaded on nano $\mathrm{ZnO}$ with particle sizes of 15 , 25 , and $38 \mathrm{~nm}$ have been carried out. The bacteria investigated in this work are Gram positive and Gram negative and it is found that the antibacterial activity of amoxicillin loaded on nano $\mathrm{ZnO}$ is insignificant for E. aerogenes and K. pneumoniae.

Acknowledgments Prof. Dr. S. Ramasamy, CSIR Emeritus Scientist and Dr. L. Palanikumar, CSIR-RA acknowledge the financial support given to them to carry-out this work under CSIR Emeritus Scientist Scheme number 21(0174)/08/EMR-II dated 28-04-2008. The authors thank National Centre for Nanoscience and Technology, University of Madras, Chennai, India, for providing HRTEM facilities. The authors thank the Reviewers for their constructive comments.

Open Access This article is distributed under the terms of the Creative Commons Attribution License which permits any use, distribution, and reproduction in any medium, provided the original author(s) and the source are credited.

\section{References}

Bernstein MP, Sandford SA, Allamandola LJ, Chang S (1994) Infrared spectrum of matrix-isolated hexamethylenetetramine in $\mathrm{Ar}$ and $\mathrm{H}_{2} \mathrm{O}$ at cryogenic temperatures. J Phys Chem 98:12206-12210

Bhosale UV, Kusum DV, Jain N (2011) Formulation and optimization of mucoadhesive nanodrug delivery system of acyclovir. J Young Pharm 3:275-283

Bhunia AK (ed) (2008) Food borne microbial pathogens: mechanisms and pathogenesis. Springer LLC, New York

Casimiro MH, Gil MH, Leal P (2007) Drug release assays from new chitosan/pHEMA membranes obtained by gamma irradiation. Nucl Instrum Methods Phys Res B 265:406-409

Chang CH, Lin YH, Hsu YM, Yeh CL, Chen YS, Chen YC, Chiou SF, Wang CC (2010) Nanoparticles incorporated in pH-sensitive hydrogels as amoxicillin delivery for eradication of Helicobacter pylori. Biomacromolecules 11:133-142

Courrier HM, Butz N, Vandamme TF (2002) Pulmonary drug delivery systems: recent developments and prospects. Crit Rev Ther Drug Carrier Syst 19:425-498

De Jong WH, Borm PJA (2008) Drug delivery and nanoparticles: applications and hazards. Int J Nanomed 3:133-149

Di Silvio L, Bonfield W (1999) Biodegradable drug delivery system for the treatment of bone infection and repair. J Mater Sci Mater Med 10:653-658

Fontana G, Licciardi M, Mansueto S, Schillaci D, Giammona G (2001) Amoxicillin-loaded polyethylcyanoacrylate nanoparticles: influence of PEG coating on the particle size, drug release rate and phagocytic uptake. Biomaterials 22:2857-2865

Gaballa A, Wang T, Ye RW, Helmann JD (2002) Functional analysis of the Bacillus subtilis Zur regul-Ion. J Bacteriol 184:6508-6514

Gautier H, Daculsi G, Merle C (2001) Association of vancomycin and calcium phosphate by dynamic compaction: in vitro characterization and microbiological activity. Biomaterials 22:2481-2487

Hamblett KJ, Senter PD, Chace DF et al (2004) Effects of drug loading on the antitumor activity of a monoclonal antibody drug conjugate. Clin Cancer Res 10:7063-7070

Horwitz E, Kagan L, Chamisha Y, Gati I, Hoffman A, Friedman M, Lavy E (2010) Novel gastroretentive controlled-release drug delivery system for amoxicillin therapy in veterinary medicine. J Vet Pharmacol Ther 34:487-493

Jayaseelan C, Abdul Rahuman A, Vishnu Kirthi A, Marimuthu S, Santhoshkumar T, Bagavan A, Gaurav K, Karthik L, Bhaskara Rao KV (2012) Novel microbial route to synthesize $\mathrm{ZnO}$ nanoparticles using Aeromonas hydrophila and their activity 
against pathogenic bacteria and fungi. Spectrochim Acta Part A 90:78-84

Jones N, Ray B, Ranjit KT, Manna AC (2008) Antibacterial activity of $\mathrm{ZnO}$ nanoparticle suspensions on a broad spectrum of microorganisms. FEMS Microbiol Lett 279:71-76

Kamaly N, Xiao Z, Valencia PM, Radovic-Moreno AF, Farokhzad OC (2012) Targeted polymeric therapeutic nanoparticles: design, development and clinical translation. Chem Soc Rev 41:29713010

Khuroo AH, Monif T, Verma PRP, Gurule S (2008) Comparison of effect of fasting and of five different diets on the bioavailability of single oral dose of amoxicillin $500 \mathrm{mg}$ capsule. Clin Res Reg Aff 25:73-86

Kim HW, Knowles JC, Kim HE (2004) Hydroxyapatite/poly( $8-$ caprolactone) composite coatings on hydroxyapatite porous bone scaffold for drug delivery. Biomaterials 25:1279-1287

Kumar DA, Dharmendra S, Jhansee M, Shrikant N, Pandey SP (2011) Development and characterization of chitosan nanoparticles loaded with amoxicillin. Int Res J Phar 2:145-511

Lu Y, Chen SC (2004) Micro and nano-fabrication of biodegradable polymers for drug delivery. Adv Drug Del Rev 56:1621-1633

Melville AJ, Rodriguez-Lorenzo LM, Forsythe JS (2008) Effects of calcinations temperature on the drug delivery behavior of ibuprofen from hydroxyapatite powders. J Mater Sci Mater Med 19:1187-1195

Ng CT, Li JJ, Bay BH, Yung LYL (2010) Current studies into the genotoxic nanomaterials. J Nucleic Acids 12

Noel SP, Courtney H, Bumgardner JD, Haggard WO (2008) Chitosan films potential drug delivery systems for antibiotics. Clin Orthop Related Res 466:1377-1382

Padmavathy N, Vijayaragaghavan R (2003) Enhanced bioactivity of $\mathrm{ZnO}$ nanoparticles-an antimicrobial study. Sci Technol Adv Mater 9:035004

Prager R, Rabsch W, Streckel W, Voigt W, Tietze E, Tschape H (2003) Molecular properties of Salmonella enterica serotype paratyphi B distinguish between its systemic and its enteric pathovars. J Clin Microbiol 41:4270-4278

Raghupathi KR, Koodali RT, Manna AC (2011) Size-dependent bacterial growth inhibition and mechanism of antibacterial activity of zinc oxide nanoparticles. Langmuir 27:4020-4028
Rasmussen JW, Martinez E, Louka P, Wingett DG (2010) Zinc oxide nanoparticles for selective destruction of tumor cells and potential for drug delivery applications. Expert Opin Drug Deliv 7:1063-1077

Roselli M, Finamore A, Garaguso I, Britti MS, Mengheri E (2003) Zinc oxide protects cultured enterocytes from the damage induced by $E$. coli. J Nutr 133:4077-4082

Sahasathian T, Kerdcholpetch T, Chanweroch A, Praphairaksit N, Suwonjandee N, Muangsin N (2007) Sustained release of amoxicillin from chitosan tablets. Arch Pharm Res 30:526-531

Saonuam P, Hiransuthikul N, Suankratay C, Malathum K, DanchaIvijitr S (2008) Risk factors for noso-comial infections caused by extended spectrum $\beta$-lactamase producing Escherichia coli or Klebsiella pneumonia in Thailand. Asian Biomed 2:485-491

Sharma PK, Pandey AC, Zolnierkiewicz G, Guskos N, Rudowicz C (2009) Relationship between oxygen defects and the photoluminescence property of $\mathrm{ZnO}$ nanoparticles: a spectroscopic view. J Appl Phys 106:094314

Smola M, Vandamme T, Sokolowski A (2008) Nanocarriers as pulmonary drug delivery systems to treat and to diagnose respiratory and non-respiratory diseases. Int J Nanomed 3:1-19

Song R, Liu Y, He L (2008) Synthesis and characterization of mercaptoacetic acid-modified $\mathrm{ZnO}$ nanoparticles. Sol Stat Sci 10:1563-1567

Venkatasubbu GD, Ramasamy S, Ramakrishnan V, Kumar J (2011) Nanocrystalline hydroxyapatite and zinc-doped hydroxyapatite as carrier material for controlled delivery of ciprofloxacin. 3 Biotech 1:173-186

Wahab R, Kim YS, Mishra A, Yun SI, Shin HS (2010) Formation of $\mathrm{ZnO}$ micro-flowers prepared via solution process and their antibacterial activity. Nanoscale Res Lett 5:1675-1681

Wu PF, Pike J, Zhang F, Chan SW (2006) Low-temperature synthesis of zinc oxide nanoparticles. Int J Appl Ceram Technol 3:272-278

Yin H, Casey PS, McCall M, Fenech M (2010) Effects of surface chemistry on cytotoxicity, genotoxicity and the generation of reactive oxygen species induced by $\mathrm{ZnO}$ nanoparticles. Langmuir 26:15399-15408

Zak AK, AbdMajid WH, Abrishami ME, Yousefi R (2011) X-ray analysis of $\mathrm{ZnO}$ nanoparticles by Williamson-Hall and sizestrain plot methods. Sol Stat Sci 13:251-256 